\title{
The prevalence of multiple sclerosis in the Southampton and South West Hampshire Health Authority
}

\author{
M H W Roberts, J P Martin, D L McLellan, S A McIntosh-Michaelis, A J Spackman
}

\begin{abstract}
A first survey of the Southampton and South West Hampshire Health Authority showed an overall prevalence of multiple sclerosis of $99 / 100000$ in a population of 417000 on 1 January 1987. This finding is similar to other recent first surveys in the South of the United Kingdom and only repeat surveys will show if case ascertainment has been more complete in these than earlier first studies in Scotland.
\end{abstract}

The prevalence of multiple sclerosis (MS) tends to be higher the more recent the study, especially in repeat studies of an area and if the population size is small, allowing more complete ascertainment. ${ }^{1}$ There have been over 30 studies of the epidemiology of MS in the United Kingdom since $1929^{2}$ but the Sutton study ${ }^{3}$ and the South East Wales studies $^{45}$ are the only ones carried out in the south of the United Kingdom since 1958. We agree with Phadke and Downie ${ }^{6}$ that "further careful epidemiological studies from comparable areas of England and Wales are urgently needed to show if the apparent high prevalence in the north-east of Scotland represents more than the fact that the region, for various reasons, has allowed a more complete ascertainment than has been possible elsewhere in the UK, with the possible exception of the Orkney and Shetland Isles."

Remarkably little is known from these studies about disablement in MS apart from a ranking of locomotor disability and clinical estimates of the prevalence of incontinence and cognitive impairment in the first North East Scotland study. ${ }^{78}$ There has, for example, been no population-based study of the problems of carers of people with MS or of the prevalence of cognitive impairment using psychometric tests.

Table 1 Sources for the provisional list of people with multiple sclerosis in the SSWHHA

General practitioners

Hospital Activity Analysis 1977-83

Southampton Multiple Sclerosis Society

Wessex Neurological Centre Admissions Book 1977-86 (address outside area excluded)

Consultant neurologists

District Dependent Disabled Register

Snowdon House Younger Disabled Unit

ARMS

Other

Total on provisional list

$=349(44 \%)$

$=323(41 \%)$
$=258 \quad(32 \%)$

$=220 \quad(28 \%)$

$=119(15 \%)$

$=76(10 \%)$

$=30 \quad(4 \%)$

$=25(3 \%)$

$=5(<1 \%)$

$=795$
The Southampton Multiple Sclerosis Survey addresses some of these issues. We report the basic epidemiological findings.

\section{Method}

The Southampton and South West Hampshire Health Authority (SSWHHA) covers a mixed rural and urban district with the New Forest to the west and with the port of Southampton to the east. The estimated 1986 midyear population was 417000 , an increase of $5.6 \%$ above the 1981 census figures..$^{10}$ Southampton is situated at a latitude of $50^{\circ} 55^{\prime}$ north and longitude of $1^{\circ} 25^{\prime}$ west.

A provisional list of people with MS was drawn from eight sources (table 1). Each general practitioner on the Family Practitioner List for the district was written to, and a follow up letter sent if no reply was obtained. The response rate was $\mathbf{9 2 \%}$. Hospital Activity Analysis data were inspected for the years 1977-83 (the latest date available at the time of the survey). Names were released by the Southampton Multiple Sclerosis Society if permission had already been obtained from the members. Names were obtained similarly from the membership list of ARMS (Action for Research in Multiple Sclerosis). The daily admissions books of the regional neurological unit, the Wessex Neurological Centre, were inspected for the years 1977-86. The names of those with a diagnosis of MS, possible MS or demyelination were recorded. Three consultant neurologists made their personal diagnostic indices available to us. Names were also sought from the District Dependent Disabled Register, which is a register of those disabled from any cause who require the help of another person to live at home. ${ }^{11}$ The records of Snowdon House, a 20-bedded Younger Disabled Unit providing relief and residential care, were inspected. The Social Services Disability Register was not consulted because it contained insufficient information about medical diagnosis.

People were considered prevalent if they were alive and usually resident within the Health Authority on 1 January 1987. Whether an address fell within the boundaries of the Health Authority was determined by reference to a map provided by the Regional Health Authority and on checking addresses with the Family Practitioner Committee when there was doubt. Usual residence was confirmed by checking with the general practitioner with whom the person was registered. The 
Table 2 Sources of prevalent people with multiple sclerosis in the SSWHHA

\begin{tabular}{lcccc}
\hline Source & Numbers (\%) & \multicolumn{3}{c}{$\begin{array}{l}\text { Known from } \\
\text { only this source }\end{array}$} \\
\hline General practitioners & $=302$ & $(73)$ & 91 & $(22)$ \\
Multiple Sclerosis Society & $=172$ & $(42)$ & 23 & $(6)$ \\
Hospital Activity Analysis 1977-83 & $=116$ & $(28)$ & 4 & $(1)$ \\
Wessex Neurological Centre Admissions & $=110$ & $(27)$ & & \\
$\quad$ Book 1977-86 & $=81$ & $(20)$ & 12 & $(3)$ \\
Consultant neurologists & $=67$ & $(16)$ & 1 & \\
District Dependent Disabled Register & $=25$ & $(6)$ & 2 & \\
ARMS & $=12$ & $(3)$ & 0 & \\
NHS residential care & $=5$ & $(1)$ & 2 & \\
Other & $=411$ & & & \\
Total on prevalent list & & &
\end{tabular}

nature of the study required that the diagnosis be confirmed by independent review of the case-notes by two of the authors (MR and DLMcL). This was carried out where possible before contacting the person. In 25 cases, the case notes indicated episodes consistent with demyelination at a single site. The general practitioners were asked to inform us if further episodes had occurred and as a result one case was reclassified as MS. The diagnosis was "rejected at interview in four cases. In three cases this had been anticipated from the case notes, but the subjects had volunteered themselves for interview. Where case notes were unavailable, the diagnosis was confirmed at interview and possible revisions of the diagnosis were discussed post-interview. Classification was according to both the Allison and Millar ${ }^{12}$ and the Poser Committee $^{13}$ diagnostic criteria except that the upper age limit of 59 for age of onset in the latter was ignored. Awareness of the diagnosis was established from case notes, general practitioners or from MS society membership. All those aware were, subject to their general practitioner's approval, written to and if a refusal to take part was not received within two weeks, they were contacted by telephone and an arrangement made for the medical registrar (MR) to interview them in their own

Table 3 Reasons for failure to interview people with multiple sclerosis in the $S S W H H A$

\begin{tabular}{lll}
\hline Died post 1.1.87 & & $=10$ \\
Left area post 1.1.87 & & $=5$ \\
Ascertained too late & & 8 \\
GP Refusal & Unaware of diagnosis & $=25$ \\
& Other & 8 \\
MS Person & Refusals & $=46$ \\
& Currently too ill & $=4$ \\
Total unable to interview & $=106 \quad(26 \%)$ \\
\hline
\end{tabular}

home. A stratified one in two sample was subsequently seen by a psychologist (SM) and a relative or carer-relative was identified at the first interview and later interviewed by a sociologist (AS). Their observations will be presented in a separate paper.

The year of onset was that recorded in the case notes, or determined at interview if this information was not in the notes. Age and sex specific prevalence rates were calculated including all Allison and Millar categories using the 1986 age structure estimates. Ninety five per cent confidence intervals were calculated on the assumption of a Poisson distribution using Schoenberg's tables, ${ }^{14}$ except where the previously published figures of other studies are quoted. An indirectly standardised prevalence ratio was calculated as in the Sutton and South East Wales studies ${ }^{34}$ using the 1961 Northern Ireland survey $^{15}$ as the reference population, to allow comparison of areas with different age structure.

The study had the approval of the District Ethical Committee and conformed with the regulations of the Data Protection Act. All data were verified by double entry using the data base $\operatorname{SIR}^{16}$ on the University of Southampton mainframe IBM 3090. Statistical analysis was performed using SPSS-X. ${ }^{17}$

\section{Results}

The provisional list consisted of 795 names and the sources, in order of numbers contributed, are shown in table 1 . After exclusion of those who had died, moved, did not have MS, did not live in the survey area or were untraceable we were left with 411 people. The sources of these names, in order of importance, are shown in table 2 with the percentage known from that source alone.

Overall $136(33 \%)$ were ascertained from only one source and 91 ( $22 \%$ of the total) were known to us solely from general practitioners. Hospital Activity Analysis proved time consuming with record linkage problems associated with separate records systems in the Regional Neurological Centre and the rest of the District. Unlike previous United Kingdom surveys departmental records, either in the form of an inpatient index or records of individual neurologists, have not been the major source of names. In Southampton, general practitioners and the local branch of the

Table 4 Comparison of recent large population prevalence surveys of multiple sclerosis in the United Kingdom (after Swingler and Compston ${ }^{4}$ )

\begin{tabular}{|c|c|c|c|c|c|}
\hline & \multirow{2}{*}{$\frac{S S W H H A}{1987}$} & \multirow{2}{*}{$\frac{\text { Sutton }}{1985(3)}$} & \multicolumn{2}{|c|}{ NE Scotland } & \multirow{2}{*}{$\frac{S E \text { Wales }}{1985(4)}$} \\
\hline & & & $1970(21)$ & $1980(5)$ & \\
\hline $\begin{array}{l}\text { Cases } \\
\text { Population (thousands) } \\
\text { Prevalence }(/ 100000)\end{array}$ & $\begin{array}{l}411 \\
417 \\
99 \\
(89-109)\end{array}$ & $\begin{array}{l}195 \\
170 \\
115 \\
(99-131)\end{array}$ & $\begin{array}{l}557 \\
440 \\
127 \\
(117-138)\end{array}$ & $\begin{array}{l}839 \\
471 \\
178 \\
(166-190)\end{array}$ & $\begin{array}{l}441 \\
377 \\
117 \\
(106-128)\end{array}$ \\
\hline $\begin{array}{l}\text { Probable }(/ 100000) \\
\text { Mean age } \\
\text { Age onset } \\
\text { Mean duration } \\
\text { Sex ratio F:M } \\
\text { Standardised prevalence ratio }\end{array}$ & $\begin{array}{l}92 \\
48 \cdot 6 \\
32 \cdot 6 \\
15 \cdot 7 \\
2 \cdot 1 \\
115 \\
(104-127)\end{array}$ & $\begin{array}{l}104 \\
49 \cdot 0 \\
34 \cdot 1 \\
15 \cdot 4 \\
2 \cdot 3 \\
129 \\
(111-147)\end{array}$ & $\begin{array}{l}105 \\
48 \cdot 2 \\
34 \cdot 2 \\
14 \cdot 4 \\
1 \cdot 6 \\
153 \\
(140-166)\end{array}$ & $\begin{array}{l}144 \\
45 \cdot 1 \\
34 \cdot 5 \\
14 \cdot 8 \\
1.9 \\
221 \\
(184-261)\end{array}$ & $\begin{array}{l}84 \\
49 \\
32 \\
16 \cdot 5 \\
2 \cdot 0 \\
139 \\
(126-150)\end{array}$ \\
\hline
\end{tabular}


Table 5 Prevalence rates of multiple sclerosis in the SSWHHA by diagnostic category

\begin{tabular}{|c|c|c|c|}
\hline Category & Number (\%) & $\begin{array}{l}\text { Prevalence } \\
(\mid 100000)\end{array}$ & $95 \% C I$ \\
\hline \multicolumn{4}{|l|}{ Allison and Millar } \\
\hline $\begin{array}{l}\text { Probable } \\
\text { Possible } \\
\text { Total }\end{array}$ & $\begin{array}{rr}384 & (93) \\
28 & (7) \\
411 & (100)\end{array}$ & $\begin{array}{r}91 \cdot 8 \\
6 \cdot 7 \\
98 \cdot 6\end{array}$ & $\begin{array}{r}83 \cdot 2-101 \cdot 3 \\
4 \cdot 5-9 \cdot 7 \\
89 \cdot 3-108 \cdot 9\end{array}$ \\
\hline \multicolumn{4}{|l|}{ Poser } \\
\hline $\begin{array}{l}\text { CDMS } \\
\text { LSDMS } \\
\text { CPMS } \\
\text { LSPMS }\end{array}$ & $\begin{array}{rr}318 & (77 \cdot 4) \\
14 & (3 \cdot 4) \\
47 & (11 \cdot 4) \\
0 & \end{array}$ & $\begin{array}{r}76 \cdot 3 \\
3 \cdot 4 \\
11 \cdot 3\end{array}$ & $\begin{array}{rr}68 \cdot 3- & 92 \cdot 3 \\
1 \cdot 9- & 5 \cdot 7 \\
8 \cdot 3- & 15 \cdot 2\end{array}$ \\
\hline $\begin{array}{l}\text { Classification unknown } \\
\text { Total in Poser } \\
\text { Suspected }\end{array}$ & $\begin{array}{rr}16 & (3 \cdot 9) \\
395 & (97 \cdot 1) \\
16 & (3 \cdot 9)\end{array}$ & $\begin{array}{r}3 \cdot 8 \\
94 \cdot 7 \\
3 \cdot 8\end{array}$ & $\begin{array}{r}2 \cdot 1-6 \cdot 3 \\
88 \cdot 0-107 \cdot 2 \\
2 \cdot 1-\quad 6 \cdot 3\end{array}$ \\
\hline
\end{tabular}

CDMS = clinically definite multiple sclerosis; LSDMS = laboratory supported definite multiple sclerosis; CPMS = clinically probable multiple sclerosis; LSPMS = laboratory supported probable multiple sclerosis; classification unknown and suspected = see text.

Multiple Sclerosis Society were the most fruitful sources. The use of these two sources alone would, however, have identified only $353(86 \%)$ of the total.

Three hundred and five $(74 \%)$ of the people identified were interviewed. This is a similar proportion seen personally as in the first North East Scotland study $(77 \%)^{18}$ and the 1985 South East Wales study $(68 \%) .{ }^{4}$ The reasons for non-interview are shown in table 3. The mean age of the non-interviewed group was 50.0 years, slightly higher than the interviewed group mean at 48.0 years but a $t$ test of this difference is not significant. Comparison of sex distribution and an estimate of the Kurtzke Expanded Disability Status Scale ${ }^{19}$ (grouped as $0-4 \cdot 5,5 \cdot 0-6 \cdot 5,7 \cdot 0-9 \cdot 5$, and unknown) from the case-notes by Chi-squared is also not significant. Although median durations did not differ significantly, a Chi-squared test of dif-

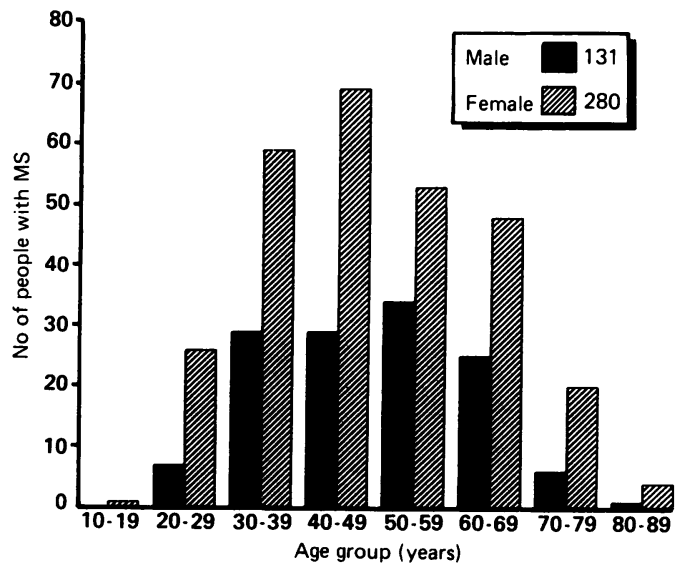

Figure 1 Age distribution by sex.

ferences in durations (grouped as under 10 years, 10 to 19 years, and 20 or over years) is significant at the $5 \%$ level. The non-interviewed group, which includes those unaware of the diagnosis, not surprisingly had a relative excess of those with a duration of under 10 years being $51 \%$ of the total as compared with $38 \%$ in the interviewed group.

Table 4 shows the main features of our population alongside the figures for four other United Kingdom studies of large populations using the Allison and Millar criteria. "Early probable and latent" and "probable" are grouped as "probable". The studies are the London Borough of Sutton 1985 study, ${ }^{3}$ the $1970^{18}$ and $1980^{6}$ North East Scotland surveys, and the 1985 South East Wales study. ${ }^{4}$ Our 411 people yielded an overall prevalence of $98.6 /$ 100000 with $95 \%$ confidence intervals of $89 \cdot 3$ to $108 \cdot 9 / 100000$. For "probable" cases the

Table 6 Comparison of the prevalence rates of multiple sclerosis between the SSWHHA and South East Wales ${ }^{4}$ using the Poser criteria

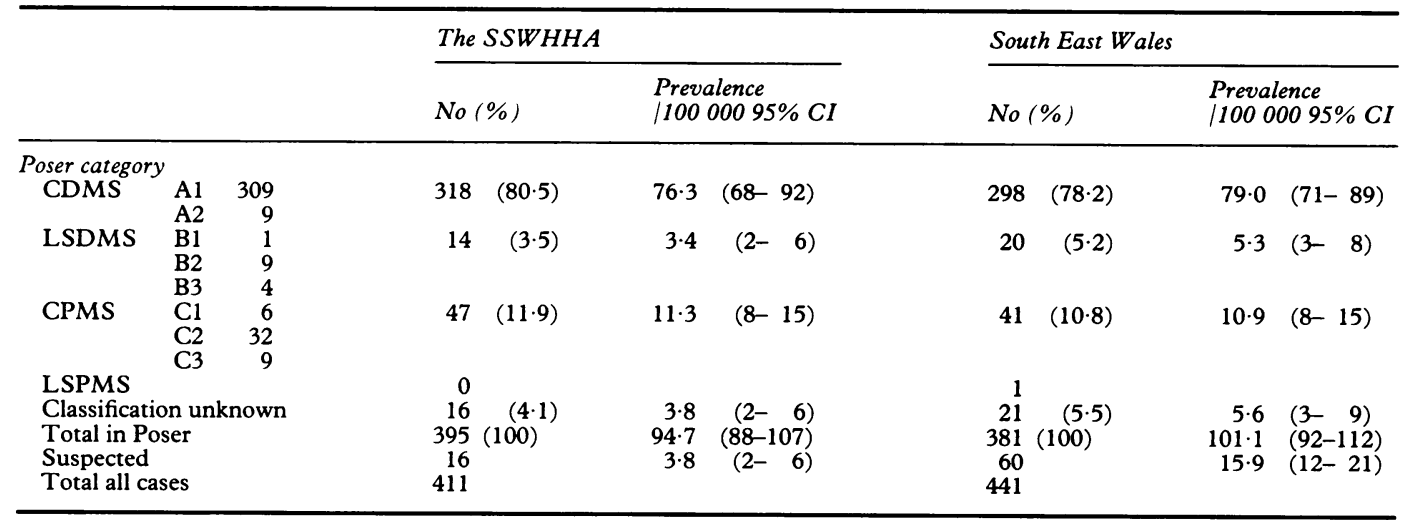

CDMS = clinically definite multiple sclerosis; LSDMS = laboratory supported definite multiple sclerosis; CPMS = clinically probable multiple sclerosis; LSPMS = laboratory supported probable multiple sclerosis; classification unknown and suspected $=$ probable
see text.

Table 7 Age and sex specific prevalence rates per 100000 of multiple sclerosis in the SSWHHA

\begin{tabular}{|c|c|c|c|c|c|c|c|c|}
\hline \multirow{2}{*}{$\begin{array}{l}\text { Age } \\
\text { Group }\end{array}$} & \multicolumn{3}{|l|}{ Male } & \multicolumn{3}{|c|}{ Female } & \multicolumn{2}{|l|}{ Total } \\
\hline & Rate & $(95 \% C I)$ & No & Rate & $(95 \% C I)$ & No & Rate & $(95 \% C I)$ \\
\hline $\begin{array}{l}15-29 \\
30-44 \\
45-59 \\
60-64 \\
65-74 \\
75+ \\
\text { All ages }\end{array}$ & $\begin{array}{r}14 \\
105 \\
143 \\
99 \\
96 \\
38 \\
64\end{array}$ & $\begin{array}{r}(6-29) \\
(76-141) \\
(105-190) \\
(49-177) \\
(56-154) \\
(10-97) \\
(54-76)\end{array}$ & $\begin{array}{r}7 \\
44 \\
48 \\
11 \\
17 \\
4 \\
131\end{array}$ & $\begin{array}{r}58 \\
226 \\
255 \\
211 \\
183 \\
31 \\
132\end{array}$ & $\begin{array}{c}(38-84) \\
(183-276) \\
(204-314) \\
(138-310) \\
(131-249) \\
(11-68) \\
(118-148)\end{array}$ & $\begin{array}{r}27 \\
94 \\
87 \\
26 \\
40 \\
6 \\
280\end{array}$ & $\begin{array}{r}35 \\
166 \\
200 \\
158 \\
144 \\
34 \\
99\end{array}$ & $\begin{array}{c}(24-49) \\
(140-197) \\
(168-237) \\
(111-218) \\
(109-187) \\
(16-63) \\
(98-109)\end{array}$ \\
\hline
\end{tabular}




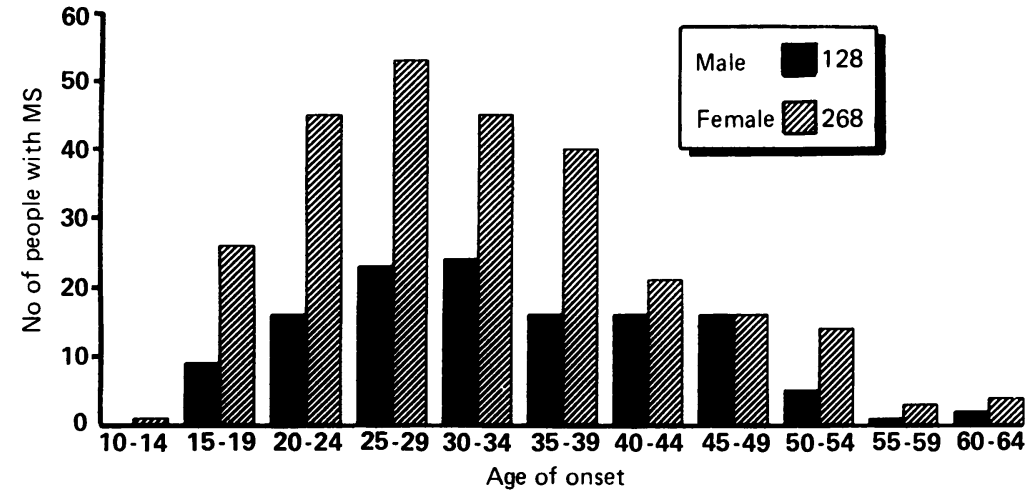

Figure 2 Age of onset by sex. distribution of age at prevalence day by sex is shown in fig 1 . Twenty five per cent were over the age of 60 and $16 \%$ were 65 or over. The distribution of age of onset by sex is shown in fig 2 and shows the typical steep rise in the third decade with a mean age of onset for females of 31.9 years and for males 33.9 years, a difference that on $t$-testing fails to reach statistical significance $(p=0.075)$. Figure 3 shows the negatively skewed distribution of duration with a median duration of 13 years. We quote mean duration for comparison but the distribution is clearly not normal.

prevalence was $91 \cdot 8 / 100000$.

The mean age was $48 \cdot 6$ years (SD $13 \cdot 9$, range 18 to 82 ), mean duration $15 \cdot 7$ years (SD $11 \cdot 2$, range $<1$ to 56 ), and the sex ratio was 2.1 females to males. The mean age of onset was 32.6 years (SD $9 \cdot 9$, range 10 to 60 ). The standardised prevalence ratio was 115 .

A comparison of the Poser Criteria and the Allison and Millar classification is in table 5 . The prevalence for all Poser categories was $94 \cdot 7 / 100000$. In 32 cases the current Poser diagnostic classification depended on paraclinical or laboratory investigations and no case depended on MRI for classification. Those in the "suspected" category are those who fall within the Allison and Millar criteria but are excluded by Poser criteria. Those in the "classification unknown" category are those in whom it was not known whether the course has been relapsing and remitting or progressive. Table 6 is a comparison of the prevalence rates using the Poser criteria in the SSWHHA and South East Wales ${ }^{4}$ which is the only other UK study to have used these criteria. The age and sex specific prevalence rates are shown in table 7 , the age intervals being determined by published population estimates. An approximation to the seven year average annual incidence rate over the years 1976-82 can be calculated from those 129 people with a disease duration of between four and 11 years. The figure, $4 \cdot 7$ / 100000 per annum, may of course be biased by migration or death. Using the method of doubling the mean duration at prevalence day, the estimate of mean duration from onset to death was 31.4 years. This method, however, may over-estimate the time to death. ${ }^{20}$ The

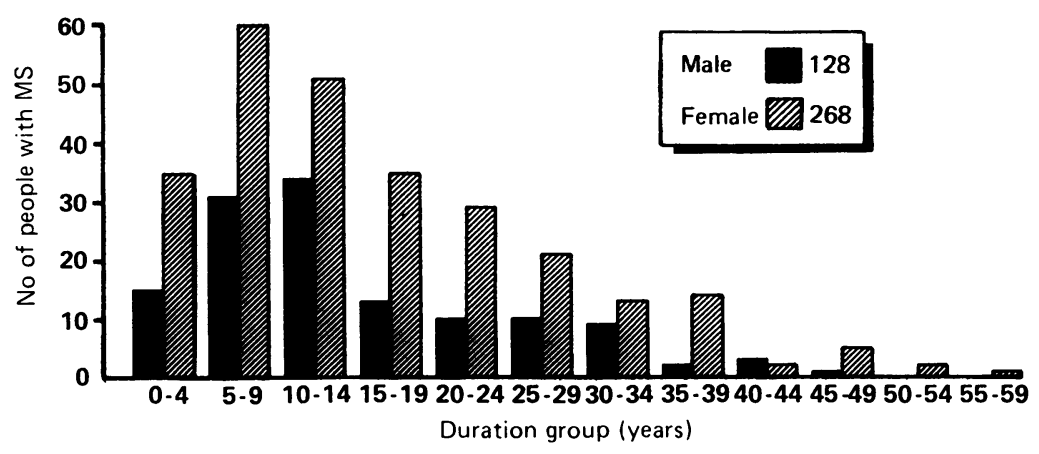

Figure 3 Duration of disease by sex.

\section{Discussion}

Our proportion (7\%) in the Allison and Millar "possible" category is unusually low. The range in studies published in the United Kingdom is from $10-28 \% .{ }^{34}$ One possible reason for our figure is that a relatively small proportion of names came from departmental indexes and this may mean that we have ascertained fewer of the less definite cases than in other United Kingdom surveys.

Diagnostic bias is another possibility. The recent Australian study ${ }^{21}$ gives some idea of how great this can be. A $10 \%$ sample of the cases in the three centres was referred to an independent judge who agreed with the diagnostic categories, using the Rose criteria, ${ }^{22}$ in $70 \%, 80 \%$ and $94 \%$ of cases but all were accepted as having MS. A formal study of agreement about exclusion was not done. There have been changes in the way the Allison and Millar criteria have been used, notably in the inclusion of paraclinical information in the latest North East Scotland study. ${ }^{236}$ In practice it may be argued that it is unrealistic to maintain that paraclinical information is ignored when judging the significance of aspects of the history and examination and that a "pure" Allison and Millar classification is no longer possible.

The Poser criteria for diagnosis are more precisely defined although we are unaware of any formal surveys of inter-observer reliability. The comparisons in table 6 show that, using the Poser criteria, the percentage distribution between different diagnostic categories was similar in our survey to that obtained in South East Wales. ${ }^{4}$ (This is not to claim that there would be agreement about the allocation of individual cases.) One objection that could be raised to the Poser criteria is that they introduce still more confounding variables, namely the availability, use and interpretation of ancillary diagnostic tests, into an already difficult area. This argument is less strong for comparisons made between different areas of the same country. We would suggest that all future United Kingdom studies should include the Poser classification. ${ }^{13}$

Elian and Dean in their 1987 study of MS in children of West Indian immigrants to London $^{24}$ were hampered by having little information on the prevalence of MS in the South of England. They stated that the "prevalence is generally estimated to be $50-70$ per 100000 , 
although intensive surveys in small populations might well show a higher figure." Since then three first studies on large populations in the South of the United Kingdom have been completed. Our figures are in fact the lowest of these.

It remains open to question whether the prevalence gradient between Northern Scotland and Southern England would be reduced by repeated studies in Southern England or whether, as has been argued to be more likely, ${ }^{4}$ case ascertainment has been more complete in these recent first studies than it was in the first North East Scotland study. The prevalence of $127 / 100000$ in 1970 was revised to $138 / 100000$ when conducting the 1973 North East Scotland study. ${ }^{25}$ However, in South East Wales the 1985 count was not significantly revised three years later ${ }^{5}$ nor was the prevalence in 1988 significantly higher than it had been in 1985 .

The recent Australian study ${ }^{2126}$ is a model for future comparative epidemiological studies in the United Kingdom because data were collected concurrently from three centres using common diagnostic criteria and there was a system for checking the manner in which the criteria were applied.

This study was funded by the Multiple Sclerosis Society of Great Britain and Northern Ireland. We are particularly grateful to the people with MS and their relatives for their willing participation in this survey, and to their general practitioners. We thank David Doulton of the University of Southampton for his help with SIR and the members of our advisory group for their support and advice.

1 Acheson ED. The epidemiology of multiple sclerosis, the pattern of the disease. In: Matthews WB, Acheson ED, Batchelor JR, Weller RO, eds. McAlpine's multiple sclerosis. Edinburgh: Churchill Livingstone, 1985:3-26.

2 Swingler RJ, Compston DAS. The distribution of multiple sclerosis in the United Kingdom. J Neurol Neurosurg Psychiatry 1986;49:1115-24.

3 Williams ES, McKeran RO. Prevalence of multiple sclerosis in a south London borough. $\mathrm{Br}$ Med J 1986;293:237-9.
4 Swingler RJ, Compston DAS. The prevalence of multiple sclerosis in South East Wales. J Neurol Neurosurg Psychiatry 1988;51:1520-4.

5 Hennessy A, Swingler RJ, Compston DAS. The incidence and mortality of multiple sclerosis in south east Wales. and mortality of multiple scierosis in south east

6 Phadke JG, Downie AW. Epidemiology of multiple sclerosis in the north-east (Grampian Region) of Scotland-an in the north-east (Grampian Regi

7 Shepherd DI. Clinical features of multiple sclerosis in northeast Scotland. Acta Neurol Scand 1979;60:218-30.

8 Shepherd DI. Multiple sclerosis in north-east Scotland (MD Thesis). Aberdeen: University of Aberdeen, 1976.

9 Office of Population Censuses and Surveys. Key population and vital statistics local and health authority areas. Population and vital statistics by area of usual residence in England and Wales 1986. London: HMSO, 1888: series VS 13 PPI, 9.

10 Wessex Regional Health Authority. Statistical yearbook, Chapter P: 1981 Census Statistics, Southampton District Health Authority. Wessex Regional Health Authority, 1983.

11 Cantrell T, Dawson J, Glastonbury G. Prisoners of handicap. Southampton: RADAR, 1985.

12 Allison RS, Millar JHD. Prevalence and familial incidence of disseminated sclerosis (A report to the Northern Ireland Hospitals Authority on the results of a three year survey). Ulster Med J 1954;23(Suppl 2):5-27.

13 Poser CM, Paty DW, Scheinberg W, et al. New diagnostic criteria for multiple sclerosis: guidelines for research protocols. Ann Neurol 1983;13(3):227-31.

14 Schoenberg BS. Calculating confidence intervals for rates and ratios. Neuroepidemiology 1983;2:314-6.

15 Millar JHD. Multiple sclerosis in Northern Ireland. In: Clifford Rose F, ed. Clinical neuroepidemiology. Tunbridge Wells: Pitman Medical, 1980:222-7.

16 SIR Version 2 User's Manual. SIR, 1980.

16 SIR Version 2 User's Manual. SIR, 1980.

17 SPSS-x User's Guide, 3rd ed. SPSS, 1988. East Scotland. Br Med J 1978;2:314-6.

19 Kurtzke JF. Rating neurologic impairment in multiple sclerosis: an expanded disability status scale (EDSS). Neurology 1983;33:1444-52.

20 Martyn CN, Osmond C. (Letter). The prevalence of multiple sclerosis in south east Wales. J Neurol Neurosurg Psychiatry 1989;52:1017.

21 Hammond SR, McLeod JG, Millingen KS, et al. The epidemiology of multiple sclerosis in three Australian cities: Perth, Newcastle and Hobart. Brain 1987;111:1-25.

22 Rose AS, Ellison GW, Myers IW, Tourtellote WW. Criteria for the clinical diagnosis of multiple sclerosis. Neurology 1976;26(2):20-2.

23 Downie AW, Phadke JD. The Chief Scientist reportsmultiple sclerosis in Northeast Scotland. Health Bull 1984;42:151-6.

24 Elian M, Dean G. Multiple sclerosis among United Kingdom-born children of immigrants from the West Indies. J Neurol Neurosurg Psychiatry 1987;50:327-32.

25 Shepherd DI, Downie AW. A further prevalence study of multiple sclerosis in north-east Scotland. $J$ Neurol Neurosurg Psychiatry 1980;43:310-5.

26 Hammond SR, English D, de Wytt $\dot{C}$, et al. The clinical profile of MS in Australia: a comparison between medium- and high-frequency prevalence zones. Neurology 1988;38:980-6. 